\title{
The Protonation Site of para-Dimethylaminobenzoic Acid Using Atmospheric Pressure lonization Methods
}

\author{
Yunfeng Chai, ${ }^{1,2}$ Guofeng Weng, ${ }^{2}$ Shanshan Shen, ${ }^{2}$ Cuirong Sun, ${ }^{1}$ Yuanjiang $\operatorname{Pan}^{2}$ \\ ${ }^{1}$ College of Pharmaceutical Sciences, Zhejiang University, Hangzhou, 310058, Zhejiang, People's Republic of China \\ ${ }^{2}$ Department of Chemistry, Zhejiang University, Hangzhou, 310027, Zhejiang, People's Republic of China
}<smiles>CN(C)c1ccc(C(=O)O)cc1</smiles>

Where is the protonation site?

\begin{abstract}
The protonation site of para-dimethylaminobenzoic acid ( $p$-DMABA) was investigated using atmospheric pressure ionization methods (ESI and APCI) coupled with collision-induced dissociation (CID), nuclear magnetic resonance (NMR), and computational chemistry. Theoretical calculations and NMR experiments indicate that the dimethyl amino group is the preferred site of protonation both in the gas phase and aqueous solution. Protonation of $p$-DMABA occurs at the nitrogen atom by ESI independent of the solvents and other operation conditions under typical thermodynamic control. However, APCI produces a mixture of the nitrogen- and carbonyl oxygenprotonated $p$-DMABA when aprotic organic solvents (acetonitrile, acetone, and tetrahydrofuran) are used, exhibiting evident kinetic characteristics of protonation. But using
\end{abstract} protic organic solvents (methanol, ethanol, and isopropanol) in APCl still leads to the formation of thermodynamically stable $N$-protonated $p$-DMABA. These structural assignments were based on the different $\mathrm{CID}$ behavior of the $\mathrm{N}$ - and $O$-protonated $p$-DMABA. The losses of methyl radical and water are the diagnostic fragmentations of the $N$ - and $O$-protonated $p$-DMABA, respectively. In addition, the $N$-protonated $p$-DMABA is more stable than the $O$-protonated $p$-DMABA in CID revealed by energy resolved experiments and theoretical calculations.

Keywords: Atmospheric pressure ionization, Protonation site, Thermodynamic and kinetic control, para-Dimethylaminobenzoic acid, Collision-induced dissociation

Received: 22 October 2014/Revised: 15 December 2014/Accepted: 15 December 2014/Published Online: 28 January 2015

\section{Introduction}

$\mathrm{P}$ rotonation is one of the fundamental reactions in chemistry and biochemistry. For example, determination of the protonation site is the key to understand the reaction mechanism of acid-catalyzed hydrolysis of various small organic molecules $[1,2]$. In enzyme-catalyzed biological reactions, protonation on the enzyme or substrate can change the interaction between each other, and then dramaticly change the reaction rate $[3,4]$. The identification of the protonation sites of organic compounds is especially important for mass spectrometrists to interpret the multistage mass spectra because the fragmentation of protonated ions is usually triggered by the positive charge brought in by protonation and the location of the proton can greatly affect the fragments observed in product ion spectra.

Electronic supplementary material The online version of this article (doi:10.1007/s13361-014-1069-7) contains supplementary material, which is available to authorized users.

Correspondence to: Yuanjiang Pan; e-mail: panyuanjiang@zju.edu.cn
Researches on the protonation and proton transfer reactions are always an important issue. A small organic molecule may accept a proton at different positions, let alone a biomolecule. Even for such a small molecule of carbon monoxide, the protonation site still needs to be seriously discussed [5]. The proton affinity (PA) is the primary criterion to determine the thermodynamically favored protonation site of a multifunctional molecule. However, the chemical environment such as solvent effect can change the preferred site of protonation $[6$, 7]. It is also interesting that a molecule can be protonated at energetically less favored position when different ionization methods are used, reflecting a kinetic influence over the protonation site [8-14]. In the case of aniline, it has no objection that the amino group is the protonation site in aqueous solution because of its good stability from solvation. However, it is a long standing dispute that the protonation of gasous aniline should be at the nitrogen atom or at the para-aromatic carbon atom, which have very similar PAs [15-18].

In recent years, a new debate about "does electrospray ionization (ESI) produce gas-phase or liquid-phase structures?" has been raised by Kass et al. [19-29]. Generally, we know that protonation occurs predominantly on the most basic site of the 
molecule to generate the thermodynamically favored protonated ions in ESI. However, ESI is an interface between liquid phase and gas phase, and so it is unclear whether the liquidphase or gas-phase basicity should be applied. Kass and Tian chose $p$-aminobenzoic acid ( $p$-ABA) as a model compound to report for the first time that when the most basic (or acidic) site of a molecule differs in solution from that in gas phase, its protonation (or deprotonation) site upon ESI can be altered through changing the spraying solvents $[24,25]$. Theoretical calculations indicated that the carbonyl oxygen of $p$-ABA was the preferred site for protonation in the gas phase while it was well-known that the most basic site of $p$-ABA was the amino group in aqueous solution. When $\mathrm{CH}_{3} \mathrm{OH} / \mathrm{H}_{2} \mathrm{O}$ was used as the ESI solvent, only the $O$-protonated ion was produced. In contrast, a mixture of the $O$ - and $N$-protonated ions were formed from $\mathrm{CH}_{3} \mathrm{CN} / \mathrm{H}_{2} \mathrm{O}$. They considered that an isomerization took place during the evaporation and desolvation process. Identification and differentiation of these two ions were accomplished by MS/MS method and infrared multiplephoto dissociation (IRMPD) spectroscopy. Campbell et al. further demonstrated the identification and separation of $N$ - and $O$-protonated $p$-ABA using differential mobility spectrometry (DMS) [26]. Williams et al. using IRMPD spectroscopy coupled with computational chemistry illustrated the role of water in stabilizing the sites of protonation in protonated $p$-ABA and its methyl ester produced by ESI, and the results suggested that the site of protonation could be changed with the alteration of the hydration states [27]. In a previous study, we found that the regioselective protonation ( $\mathrm{O}$ - or $\mathrm{N}$-protonation) of $p$-(dimethylamino)chalcone by ESI was in accordance with that observed in the case of $p$-ABA. We also revealed that the protonation site of the $[\mathrm{M}+\mathrm{H}]^{+}$ion of $p$-(dimethylamino)chalcone produced by atmospheric pressure chemical ionization (APCI) could differ on the basis of the solvent system and operation condition [28]. Joyce and Richards reported the kinetic control of protonation process in ESI by reference to the MS and MS/ MS spectra of crizotinib and two related impurities because of steric hindrance at the most basic site [29]. These compounds contain two possible protonation sites, a pyridine nitrogen and a piperidine nitrogen (a secondary amine) and the piperidine nitrogen is the preferred site of protonation for crizotinib itself. But in the two impurities, although alkyl substitution on the piperidine nitrogen (a tertiary amine) increases its PA, protonation at the pyridine nitrogen becomes more favorable instead.

Herein, we studied the protonation behavior of $p$ dimethylaminobenzoic acid ( $p$-DMABA) by atmospheric pressure ionization methods including ESI and APCI. Although, the $p$-DMABA has a similar structure to $p$-ABA, the PA at each local functionality of $p$-DMABA has a great difference from that of $p$-ABA. As a consequence, the protonation behavior of $p$-DMABA in atmospheric pressure ionization mass spectrometry is different from that of $p$-ABA and other reported examples, which represents a very special and interesting case.

\section{Experimental}

\section{Materials}

$p$-(Dimethylamino)benzoic acid, methyl $p$ (dimethylamino)benzoate, and $N, N$-dimethylaniline were all commercial products, and were used as received. Methyl $p$ (trimethylammonium)benzoate iodide was synthesized and purified following reported procedures [30]. The structure was confirmed by NMR spectroscopy and mass spectrometry. All the solvents used in mass spectrometric experiments were chromatographic grade.

\section{Mass Spectrometry}

All mass spectrometry experiments were performed on a commercial ion trap mass spectrometer (Varian 500-MS) equipped with an ESI or APCI interface. Nitrogen was used as the nebulizing gas and drying gas. A solution containing the analytes $\left(10 \mu \mathrm{g} \mathrm{mL} L^{-1}\right)$ was infused into the mass spectrometer with a syringe pump at a flow rate of $10 \mu \mathrm{L} \mathrm{min}{ }^{-1}$. Unless stated otherwise, the general instrumental conditions were as described below.

ESI in positive ion mode: spray chamber temperature $50^{\circ} \mathrm{C}$, nebulizer gas pressure $35 \mathrm{psi}$, drying gas pressure $10 \mathrm{psi}$, drying gas temperature $350^{\circ} \mathrm{C}$, needle voltage $5000 \mathrm{~V}$, spray shield voltage $600 \mathrm{~V}$, capillary voltage $75 \mathrm{~V}$, rf loading $75 \%$, scan mass range $50-600 \mathrm{~m} / \mathrm{z}$.

APCI in positive ion mode: spray chamber temperature $65^{\circ} \mathrm{C}$, nebulizer gas pressure $35 \mathrm{psi}$, drying gas pressure $10 \mathrm{psi}$, drying gas temperature $350^{\circ} \mathrm{C}$, vaporizer gas pressure $20 \mathrm{psi}$, vaporizer gas temperature $350^{\circ} \mathrm{C}$, corona current $5 \mu \mathrm{A}$, spray shield voltage $600 \mathrm{~V}$, capillary voltage $75 \mathrm{~V}$, rf loading $75 \%$, scan mass range $50-600 \mathrm{~m} / z$.

The collision-induced dissociation (CID) mass spectra were obtained with helium as the collision gas after isolation of the target precursor ions. The isolation window was $1 \mathrm{~m} / \mathrm{z}$. The fragmentation amplitude was adjusted properly to give the desired mass spectra.

\section{Nuclear Magnetic Resonance}

${ }^{13} \mathrm{C}$ NMR data were acquired on a Bruker Advance III 500 spectrometer (Bruker BioSpin, Switzerland) operating at $125 \mathrm{MHz}$ for ${ }^{13} \mathrm{C}$ detection. All the samples were first dissolved in $\mathrm{CD}_{3} \mathrm{CN}$. The ${ }^{13} \mathrm{C}$ NMR spectra were recorded following the addition of equivalent volume of $\mathrm{H}_{2} \mathrm{O}$ or $1 \mathrm{M} \mathrm{HCl}$ aqueous solution, respectively.

\section{Computations}

Geometry optimizations were carried out at the Becke 3-parameter hybrid exchange and Lee-Yang-Parr (B3LYP) correlation density functional theory (DFT) calculations along with the 6-311++G(2d,p) basis set using Gaussian 03 [31]. Vibrational frequency analysis was performed at the same theoretical level. The resulting energies reported herein corresponded to the electronic and thermal energies at $298 \mathrm{~K}$ corrected for zero-point energy (ZPE). In some cases, G3 
<smiles>COC(O)=C1C=CC(=[N+](C)C)C=C1</smiles>

Scheme 1. Mesomeric structures of $p$-DMABA

energies were also computed. The proton affinities (PAs) were calculated using the semiclassical approximation: $\mathrm{PA}=-\Delta \mathrm{E}+$ 5/2RT, where $\Delta \mathrm{E}=\mathrm{E}\left(\mathrm{BH}^{+}\right)-\mathrm{E}(\mathrm{B})[32]$.

\section{Results and Discussion}

\section{Gas-Phase Protonation Site}

The protonation site of $p$-DMABA is not immediately obvious. Although the proton affinity (PA) of $N, N$-dimethylaniline is higher than that of benzoic acid (i.e., $\mathrm{PA}\left(\mathrm{PhNMe}_{2}\right)=$
$941.1 \mathrm{~kJ} \mathrm{~mol}^{-1}$ and $\left.\mathrm{PA}(\mathrm{PhCOOH})=821.1 \mathrm{~kJ} \mathrm{~mol}^{-1}\right)$ [33], this does not guarantee that the $N, N$-dimethyl group is the most basic site in $p$-DMABA. The effect of each substituent (electron-donating effect of $\mathrm{N}, \mathrm{N}$-dimethyl and electron-withdrawing effect of carboxy) on the proton affinity of the other must be considered. Because of the conjugate structure of $p$-DMABA, the lone pair electrons of $\mathrm{N}$ can be partially dispersed to the phenyl ring and carboxyl group. Some resonance forms (Scheme 1) contribute significantly to the general energy of $p$-DMABA. Therefore, in the neutral $p$-DMABA, the dimethylamino group is expected to be in a coplanar arrangement with the benzene ring with the nitrogen in a nearly $\mathrm{sp}^{2}$ hybridized state. The nitrogen possesses partial positive charge, which is unfavorable for protonation, whereas the carbonyl oxygen possesses partial negative charge, which is favorable for proton attachment.

To determine the most basic site of $p$-DMABA, we carried out B3LYP and G3 calculations (Table 1). $N$-protonation was found to be thermodynamically preferred over $O$-protonation (this $O$ means the carbonyl oxygen, here and also in the following text) by $4.6 \mathrm{~kJ} \mathrm{~mol}^{-1}$ (B3LYP) and $24.6 \mathrm{~kJ} \mathrm{~mol}^{-1}$

Table 1. Computed Relative Energies of Protonated $p$-DMABA

\begin{tabular}{|c|c|c|c|c|c|c|}
\hline \multirow{2}{*}{ Compound } & \multirow{2}{*}{$\begin{array}{c}\text { Protonation } \\
\text { site }\end{array}$} & \multicolumn{2}{|c|}{$\mathrm{E}_{\text {Relative }}\left(\mathrm{kJ} \mathrm{mol}^{-1}\right)$} & \multicolumn{3}{|c|}{$\mathrm{PA}\left(\mathrm{kJ} \mathrm{mol}^{-1}\right)$} \\
\hline & & B3LYP $^{a}$ & G3 & B $3 L Y P^{a}$ & G3 & Experiment ${ }^{c}$ \\
\hline & $\mathrm{C}=\mathrm{O}$ & 4.6 & 24.6 & 904.3 & 895.3 & \\
\hline & $\mathrm{OH}$ & $45.5^{\mathrm{b}}$ & & & & \\
\hline & $\mathrm{C} 1$ & 43.6 & & & & \\
\hline & $\mathrm{C} 2$ & 129.9 & & & & \\
\hline & $\mathrm{C} 3$ & 29.6 & & & & \\
\hline & $\mathrm{C} 4$ & 199.5 & & & & \\
\hline & $\mathrm{N}$ & 0 & 0 & 908.9 & 919.9 & \\
\hline & $\mathrm{C}=\mathrm{O}$ & & & 833.0 & 824.7 & 821.1 \\
\hline & $\mathrm{N}$ & & & 938.1 & 944.7 & 941.1 \\
\hline
\end{tabular}


(G3). Through comparing the PA values obtained from calculation with that from experiment for benzoic acid and $N, N$-dimethylaniline, we found that the B3LYP method is good but the high-level G3 method is better [24]. The G3predicted PA values are in excellent accord with the experimental data. Protonation at the hydroxy oxygen atom and the ring carbon atoms were also considered, but these species were found to be less stable than the $O$ - and $N$-protonated ions. As a consequence, the thermodynamically preferred protonation site of $p$-DMABA in the gas phase is the nitrogen atom.

\section{Liquid-Phase Protonation Site}

It is well-known from basic organic chemistry that amino group is the more favored protonation site in the liquid phase. The ${ }^{13} \mathrm{C}$ NMR resonances of $p$-DMABA as well as other structurally related molecules were recorded to determine the most basic site of $p$-DMABA in solution. Their ${ }^{13} \mathrm{C}$ chemical shifts are summarized in Table 2 and the spectra are presented in the Supporting Information. Laufer et al. found that $p$-ABA exists almost exclusively as the "molecular" species but not the "Zwitterion" species at neutral pH by ${ }^{13} \mathrm{C}$ NMR method [34]. Upon $N$-protonation of $p$-ABA, the carbon resonances of $\mathrm{C} 1$ and $\mathrm{C} 3$ shift downfield, the carbon resonance of $\mathrm{C} 4$ shifts upfield, the carbon resonance of $\mathrm{C} 2$ shows almost no change, and the carbon resonance of C6 (the carbonyl) shifts upfield a little [34]. The ${ }^{13} \mathrm{C}$ chemical shifts of $p$-DMABA and its methyl ester under neutral and acidic solvents were found to be quite similar to those observed in $p$-ABA. Furthermore, the ${ }^{13} \mathrm{C}$ chemical shifts of protonated methyl $p$-(dimethylamino)benzoate is very close to that of methyl $p$-(trimethylammonium)benzoate cation, the positive charge of which is undoubtedly fixed on the nitrogen. Upon

Table 2. ${ }^{13} \mathrm{C}$ Chemical Shifts Determined for $p$-Aminobenzoic Acid Derivatives

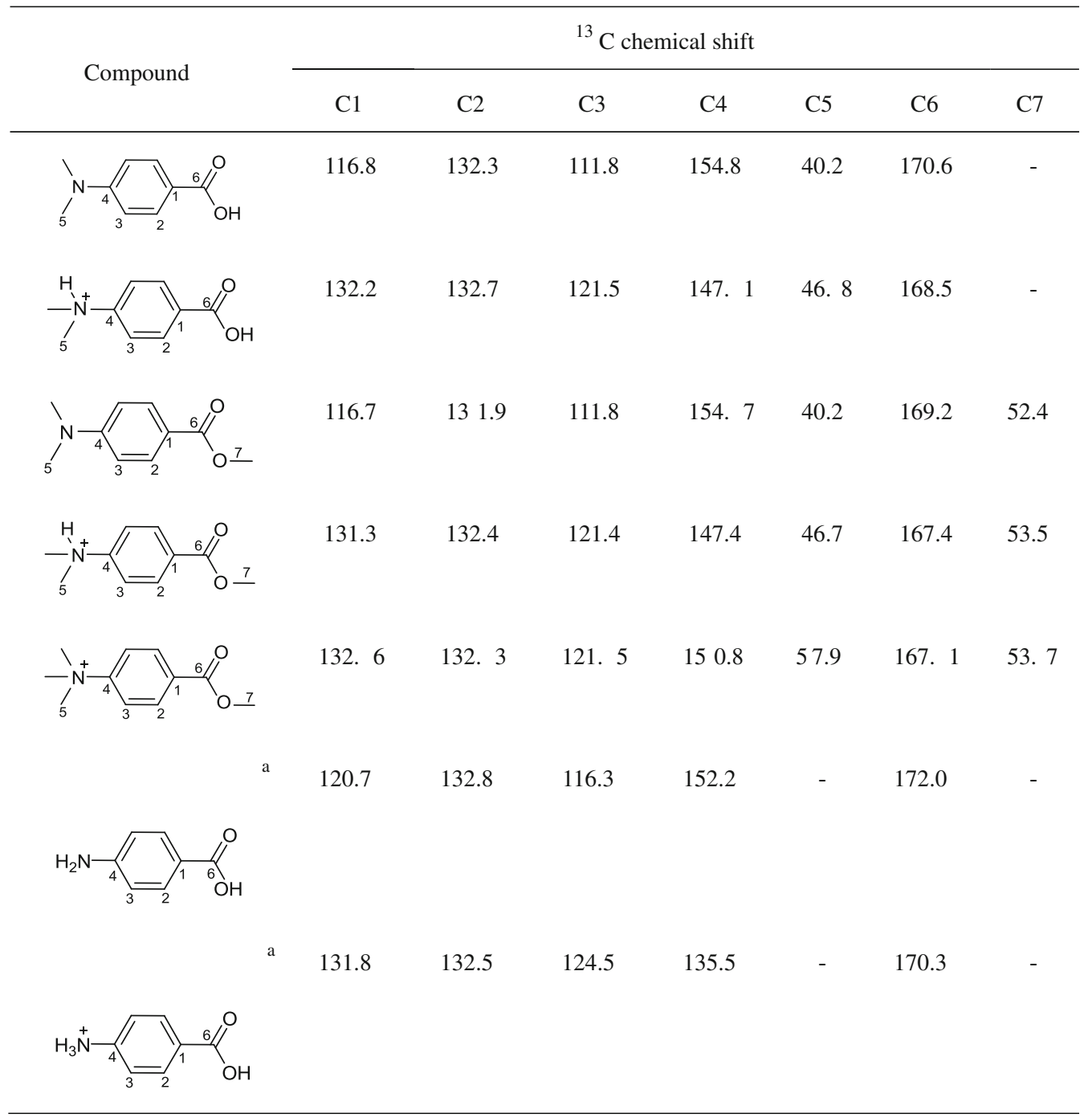


$N$-protonation, the ${ }^{13} \mathrm{C}$ chemical shift of $N$-methyl obviously shifts downfield. All these results indicate that the nitrogen of $p$ DMABA is also the preferred protonation site in the liquid phase.

\section{Protonation Site in Electrospray Ionization}

The added proton is usually the driving force for fragmentation of protonated molecules $[35,36]$. As a consequence, the fragmentation behavior of a protonated molecule can be different when the proton is attached to different positions, and so the determination of the actual protonation site may be achieved with the aid of collision-induced dissociation (CID) mass spectrometry. For protonated $p$-DMABA, the fragmentations of $O$ and $N$-protonated species are expected to produce different product ions (Scheme 2). Loss of methyl radical from the $\mathrm{N}$ protonated $N$-methyl compounds is commonly observed in mass spectrometry [37, 38]. Fragmentation of $N$-protonated $p$-DMABA gives rise to a radical cation at $m / z 151$. For the fragmentation of $O$-protonated $p$-DMABA, the proton first migrates from the carbonyl oxygen to the hydroxyl oxygen and then loss of water takes place, generating an acylium ion at $m / z$ 148. Proton transfer between $\mathrm{C}=\mathrm{O}$ and $\mathrm{N}$ via ring walk in CID may be possible [39], but the previous studies on an analogous $p$-aminobenzoic acid indicate this process should not occur [24]. The product ions $\mathrm{m} / \mathrm{z} 151$ and 148 can be diagnostic ions for $N$-protonated and $O$-protonated $p$-DMABA, respectively.

The CID mass spectra of the methyl $p$-(trimethylammonium) benzoate cation $(m / z 194)$ and the $[\mathrm{M}+\mathrm{H}]^{+}$ions of $p$-DMABA $(\mathrm{m} / z$ 166) generated by ESI are shown in Figure 1 and their fragmentation assignments are given in Supplementary Scheme S1. Loss of methyl radical is the major fragmentation pathway of methyl $p$-(trimethylammonium)benzoate cation, the positive charge of which is definitively fixed on the nitrogen (Figure 1a). A predominant product ion $\mathrm{m} / \mathrm{z} 151$ is observed in the fragmentation of protonated $p$-DMABA (Figure 1b), which indicates the precursor ion mainly has a $N$-protonated configuration. The relative abundance of $\mathrm{m} / \mathrm{z} 148$ is consistently very low under various ESI spraying conditions and CID parameters. The ESI mass spectrum is a reflection of the state of protonation of the molecule in solution because the protonated ion is first formed in the liquid phase and then it is transferred to the gas<smiles>C[14C](=[18O])c1ccc(C(=O)O)cc1</smiles><smiles>CN(C)c1ccc(C(=O)OCC(=O)O)cc1</smiles>

Scheme 2. Proposed fragmentation pathways of $\mathrm{N}$ - and $O$-protonated $p$-DMABA in tandem mass spectrometry
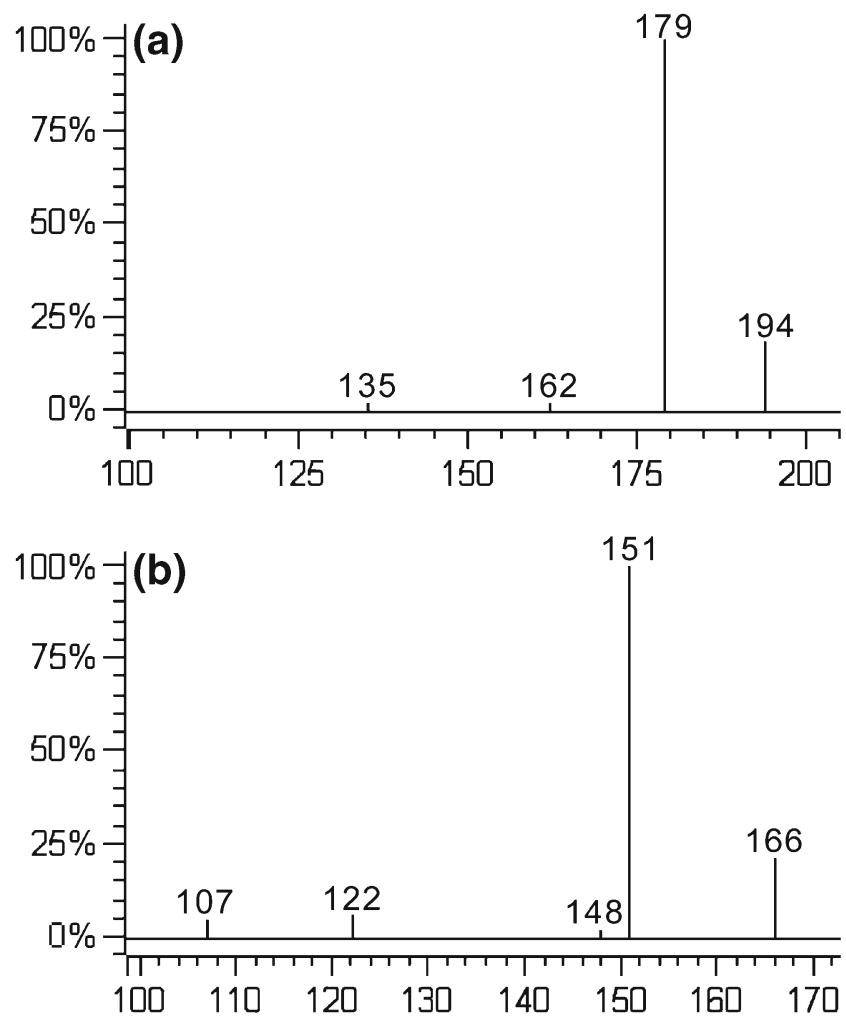

Figure 1. CID mass spectra of (a) methyl $p$-(trimethylammonium) benzoate cation, and (b) protonated $p$-DMABA generated by ESI. When different solvents (including $\mathrm{CH}_{3} \mathrm{OH}, \mathrm{CH}_{3} \mathrm{OH}$ / $\mathrm{H}_{2} \mathrm{O}, \mathrm{CH}_{3} \mathrm{CN} / \mathrm{H}_{2} \mathrm{O}$ ) were used, the $\mathrm{CID}$ mass spectra show little difference

phase through spraying and desolvation [40]. The $N$-protonated $p$-DMABA, as a stable liquid-phase structure, is formed at the first stage of ESI, and this structure is preserved deservedly in the desolvation process because it is also the most thermodynamically stable isomeric ion in the gas phase among all the protonated $p$-DMABA.

\section{Protonation Site in Atmospheric Pressure Chemical Ionization}

It seems only the $N$-protonated $p$-DMABA can be generated in mass spectrometry because of its thermodynamic stability both in the liquid phase and gas phase. Unbelievably, at first glance, the $O$-protonated $p$-DMABA could be produced by APCI. In APCI, the sample solution first evaporates to form a gaseous state, and then the analyte ions are formed through corona discharge and ion/molecule reactions; thus, it seems reasonable that the gas-phase thermodynamically favored ion should be formed [41-43]. The CID spectra of the $[\mathrm{M}+\mathrm{H}]^{+}$ion of $p$ DMABA generated by APCI from different solvents exhibit clear difference, as shown in Figure 2. The product ion $\mathrm{m} / \mathrm{z} 148$ can be competitively generated when aprotic solvents (acetonitrile, acetone, and tetrahydrofuran) are used, and it is the dominant product ion by using tetrahydrofuran as the solvent. This result indicates that the $O$-protonated $p$-DMABA can be 

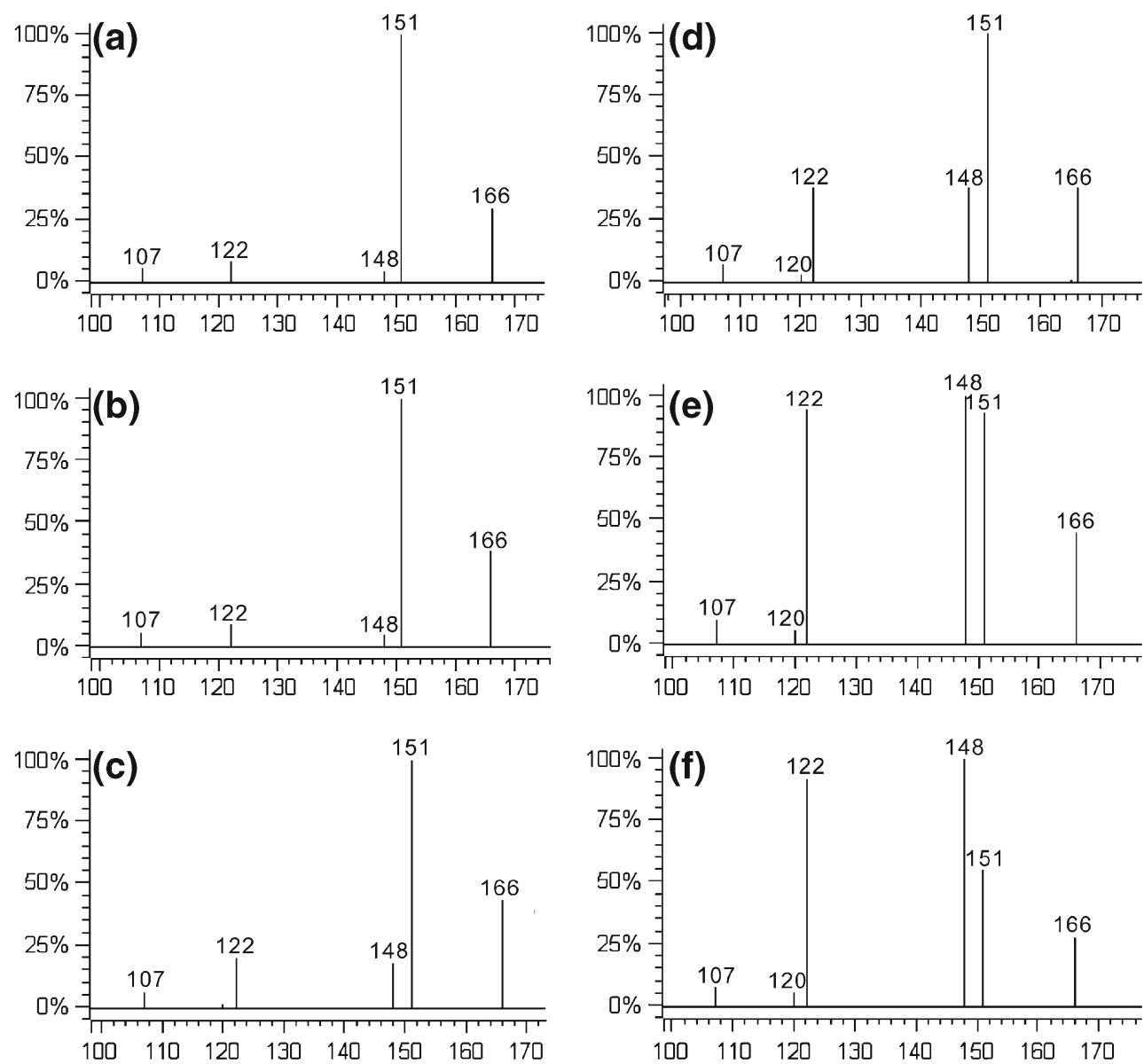

Figure 2. CID mass spectra of the protonated $p$-DMABA generated by APCl from (a) methanol, (b) ethanol, (c) isopropanol, (d) acetonitrile, (e) acetone, and (f) tetrahydrofuran. All other parameters were held constant

produced in APCI using appropriate solvents under kinetic control. Furthermore, when the protic solvents, including methanol, ethanol, and isopropanol, are used in APCI, the formation of $N$-protonated $p$-DMABA is still favored. In addition, it is noteworthy that both the $N$-protonated and $O$-protonated $p$-DMABA may lose $\mathrm{CO}_{2}$, but loss of $\mathrm{CO}_{2}$ from the $O$ protonated $p$-DMABA is easier because the product ion $\mathrm{m} / \mathrm{z}$ 122 also becomes much more abundant as the increase of the intensity of product ion $\mathrm{m} / \mathrm{z} 148$.

\section{Stability of the N-Protonated Versus O-Protonated $p$-DMABA}

The $N$ - and $O$-protonated $p$-DMABA should have different stability besides their different fragmentation patterns. To study the stability of $N$ - and $O$-protonated $p$-DMABA, theoretical calculations were carried out using the DFT at B3LYP/6$311+\mathrm{G}(2 \mathrm{~d}, \mathrm{p})$ level of theory. The energy requirements for the fragmentation of these two ions were computed and compared (Figure 3). Loss of methyl radical from the $N$-protonated $p$-DMABA requires $240.0 \mathrm{~kJ} \mathrm{~mol}^{-1}$. The energy barrier of proton transfer in water loss for the $O$-protonated $p$-DMABA is only $188.5 \mathrm{~kJ} \mathrm{~mol}^{-1}$. Thus, the energy threshold of water loss for the $O$-protonated $p$-DMABA is $51.5 \mathrm{~kJ} \mathrm{~mol}^{-1}$ lower than that of methyl radical loss for the $N$-protonated $p$-DMABA. The theoretical calculation indicates that the $N$-protonated $p$ DMABA is more stable than the $O$-protonated $p$-DMABA.

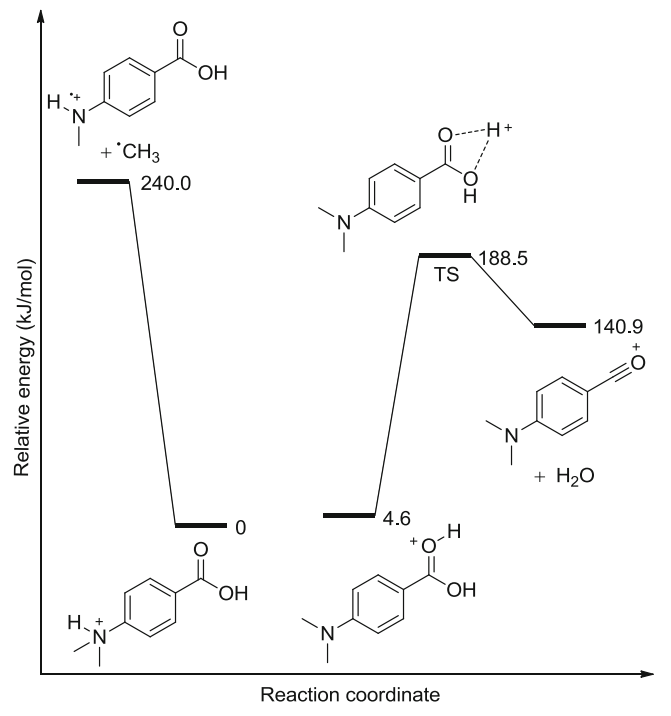

Figure 3. Potential energy diagram for the fragmentation of protonated $p$-DMABA using DFT calculations 
To further confirm the stability of $N$ - and $O$-protonated $p$ DMABA, CID experiments at different collision energies were performed. The $[\mathrm{M}+\mathrm{H}]^{+}$ion of $p$-DMABA $(m / z$ 166) generated by APCI from THF should be a mixed $N$-protonated ion and $O$-protonated ion. As shown in Figure 4 (the left three mass spectra a-1, b-1, and c-1), with the increase of collision energy, the relative abundance of product ion $\mathrm{m} / \mathrm{z} 151$ (relative to product ion $\mathrm{m} / \mathrm{z} 148$ ) also rises, which means the $N$-protonated $p$-DMABA displays higher stability toward collisional decomposition. In MS/MS experiment of protonated ion $m / z 166$, the $O$-protonated $p$-DMABA is more prone to dissociate than the $N$-protonated $p$-DMABA, so the remaining precursor ion $\mathrm{m} / \mathrm{z}$ 166 is mainly the $N$-protonated $p$-DMABA. Indeed, as shown in Figure 4 (the right three mass spectra a-2, b-2, and c-2), when the residual parent ion $m / z 166$ in $\mathrm{MS}^{2}$ is subjected to $\mathrm{MS}^{3}$, the relative abundance of product ion $\mathrm{m} / z 151$ is higher than that of product ion $\mathrm{m} / z$ 148, and the product ion $\mathrm{m} / z 151$ is even more dominant when the collision energy in $\mathrm{MS}^{2}$ is higher (because more $O$-protonated $p$-DMABA in $\mathrm{MS}^{2}$ has been broken). These experimental results not only demonstrate the $N$-protonated $p$-DMABA is more stable than the $O$-protonated $p$-DMBA but also reconfirm the $[\mathrm{M}+\mathrm{H}]^{+}$ion of $p$-DMABA generated by APCI with THF as the solvent is a mixture of $\mathrm{N}$ - and $\mathrm{O}$ protonated ions.
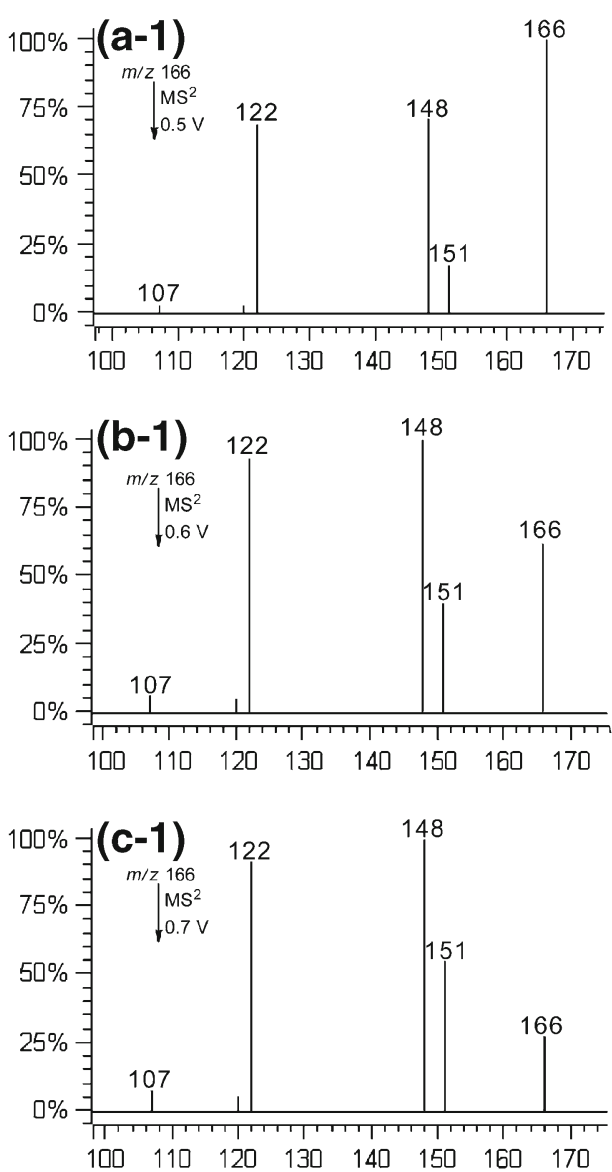

\section{Conclusions}

The nitrogen atom is the thermodynamically favored protonation site of para-dimethylaminobenzoic acid ( $p$ DMABA) both in the gas phase and aqueous solution that was revealed by the ${ }^{13} \mathrm{C}$ nuclear magnetic resonance and theoretical calculations. The tandem mass spectrometry technique showed that protonation of $p$-DMABA at atmospheric pressure ionization yields two isomeric ions involving nitrogen- and carbonyl oxygen-protonated structures, which could be distinguished via the structurally diagnostic fragments (losses of ${ }^{-} \mathrm{CH}_{3}$ and $\mathrm{H}_{2} \mathrm{O}$, respectively), and the $\mathrm{N}$-protonated ion is more stable than the $O$-protonated ion. The electrospray ionization only produces the thermodynamically preferable $N$-protonated $p$-DMABA, whereas atmospheric pressure chemical ionization can generate the $N$ - or $O$-protonated $p$ DMABA through altering the solvent in which the sample is dissolved. These findings are different from some related studies on para-aminobenzoic acid. This study inspired us to pay more attention to the protonation process of atmospheric pressure ionization when we use such mass spectrometers in qualitative and quantitative analysis.
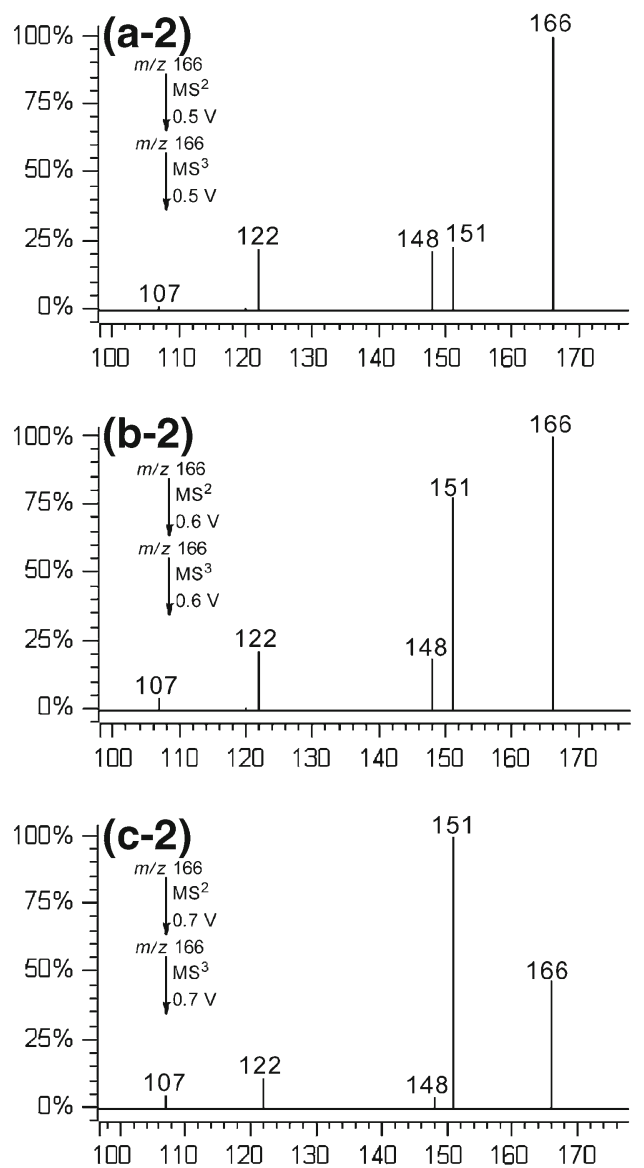

Figure 4. $\mathrm{MS}^{2}$ and $\mathrm{MS}^{3}$ mass spectra of protonated $p$-DMABA generated by APCl from THF with different collision energies (fragmentation amplitudes are shown in the spectra) 


\section{Acknowledgments}

The authors acknowledge support for this work by the National Science Foundation of China (no. 21025207, 21405137).

\section{References}

1. Brown, R.S., Bennet, A.J., Slebocka-Tilk, H.: Recent perspectives concerning the mechanism of $\mathrm{H}_{3} \mathrm{O}^{+}$- and $\mathrm{OH}^{-}$-promoted amide hydrolysis. Acc. Chem. Res. 25, 481-488 (1992)

2. Wang, B., Cao, Z.: Acid-catalyzed reactions of twisted amides in water solution: competition between hydration and hydrolysis. Chem. Eur. J. 17, 11919-11929 (2011)

3. Ji, C.G., Zhang, Z.H.: Understanding the molecular mechanism of enzyme dynamics of ribonuclease A through protonation/deprotonation of HIS48. J. Am. Chem. Soc. 133, 17727-17737 (2011)

4. Ferrer, S., Silla, E., Tuñón, I., Oliva, M., Moliner, V., Williams, I.H.: Dependence of enzyme reaction mechanism on protonation state of titratable residues and QM level description: lactate dehydrogenase. Chem. Commun. 47, 5873-5875 (2005)

5. Jansen, H.B., Ros, P.: A study of the effect of protonation on the electronic structure of the diatomic molecules BF, $\mathrm{CO}$, and $\mathrm{N}_{2}$. Theoret. Chim. Acta 21, 199-204 (1971)

6. Raczyńska, E.D., Makowski, M., Górnicka, E., Darowska, M.: Ab Initio studies on the preferred site of protonation in cytisine in the gas phase and water. Int. J. Mol. Sci. 6, 143-156 (2005)

7. Riand, J., Chenon, M.T., Lumbroso-Bader, N.: Proton and carbon-13 nuclear magnetic resonance studies of substituted pyrimidines. 2 . Monoprotonation of methyl- and aminopyrimidines. J. Am. Chem. Soc. 99, 6838-6845 (1977)

8. Wood, K.V., Burinsky, D.J., Cameron, D., Cooks, R.G.: Site of gas-phase cation attachment. Protonation, methylation, and ethylation of aniline, phenol, and thiophenol. J. Org. Chem. 48, 5236-5242 (1983)

9. Nacson, S., Harrison, A.G., Davidson, W.R.: Effect of method of ion preparation on low-energy collision-induced dissociation mass spectra. Org. Mass Spectrom. 21, 317-319 (1986)

10. Mason, R., Milton, D., Harris, F.: Proton transfer to the fluorine atom in fluorobenzene: a dramatic temperature dependence in the gas phase. J. Chem. Soc. Chem. Commun. 1453-1455 (1987). doi:10.1039/ C39870001453

11. Weisz, A., Cojocaru, M., Mandelbaum, A.: Site-specific gas-phase protonation of 2-t-butylmaleates and 2-t-butylsuccinates upon chemical ionization: stereochemical effects and kinetic control. J. Chem. Soc. Chem. Commun. 331-332 (1989). doi:10.1039/C39890000331

12. Nakata, H., Suzuki, Y., Shibata, M., Takahashi, K., Konishi, H., Takeda, N., Tatematsu, A.: Chemical ionization mass spectrometry of bifunctional compounds. The behavior of bifunctional compounds on protonation. Org. Mass Spectrom. 25, 649-654 (1990)

13. Vais, V., Etinger, A., Mandelbaum, A.: Intramolecular proton transfers in stereoisomeric gas-phase ions and the kinetic nature of the protonation process upon chemical ionization. J. Mass Spectrom. 34, 755-760 (1999)

14. Denekamp, C., Mandelbaum, A.: Proton transfer via strained transition states in the elimination of alcohols from $\mathrm{MH}^{+}$ions of stereoisomeric diethers and hydroxy esters upon chemical ionization and collision-induced dissociation. J. Mass Spectrom. 36, 422-429 (2001)

15. Nold, M.J., Wesdemiotis, C.: Differentiation of $N$ - from $C$-protonated aniline by neutralization-reionization. J. Mass Spectrom. 31, 1169-1172 (1996)

16. Smith, R.L., Chyall, L.J., Beasley, B.J., Kenttämaa, H.I.: The site of protonation of aniline. J. Am. Chem. Soc. 117, 7971-7973 (1995)

17. Russo, N., Toscano, M., Grand, A., Mineva, T.: Proton affinity and protonation sites of aniline. Energetic behavior and density functional reactivity indices. J. Phys. Chem. A 104, 4017-4021 (2000)

18. Roy, R.K., de Proft, F., Geerlings, P.: Site of protonation in aniline and substituted anilines in the gas phase: a study via the local hard and soft acids and bases concept. J. Phys. Chem. A 102, 7035-7040 (1998)

19. Tian, Z., Pawlow, A., Poutsma, J.C., Kass, S.R.: Are carboxyl groups the most acidic sites in amino acids? Gas-phase acidity, H/D exchange experiments, and computations on cysteine and its conjugate base. J. Am. Chem. Soc. 129, 5403-5407 (2007)

20. Tian, Z., Kass, S.R.: Does electrospray ionization produce gas-phase or liquid-phase structures? J. Am. Chem. Soc. 130, 10842-10843 (2008)
21. Tian, Z., Wang, X.-B., Wang, L.-S., Kass, S.R.: Are carboxyl groups the most acidic sites in amino acids? Gas-phase acidities, photoelectron spectra, and computations on tyrosine, $p$-hydroxybenzoic acid, and their conjugate bases. J. Am. Chem. Soc. 131, 1174-1181 (2009)

22. Steill, J.D., Oomens, J.: Gas-phase deprotonation of $p$-hydroxybenzoic acid investigated by IR spectroscopy: solution-phase structure is retained upon ESI. J. Am. Chem. Soc. 131, 13570-13571 (2009)

23. Schröder, D., Buděšínský, M., Roithová, J.: Deprotonation of $p$ hydroxybenzoic acid: does electrospray ionization sample solution or gas-phase structures? J. Am. Chem. Soc. 134, 15897-15905 (2012)

24. Tian, Z., Kass, S.R.: Gas-phase versus liquid-phase structures by electrospray ionization mass spectrometry. Angew. Chem. Int. Ed. 48, $1321-1323$ (2009)

25. Schmidt, J., Meyer, M.M., Spector, I., Kass, S.R.: Infrared multiphoton dissociation spectroscopy study of protonated $p$-aminobenzoic acid: does electrospray ionization afford the amino- or carboxy-protonated ion? J. Phys. Chem. A. 115, 7625-7632 (2011)

26. Campbell, J.L., Yves Le Blanc, J.C., Schneider, B.B.: Probing electrospray ionization dynamics using differential mobility spectrometry: the curious case of 4 aminobenzoic acid. Anal. Chem. 84, 7857-7864 (2012)

27. Chang, T.M., Prell, J.S., Warrick, E.R., Williams, E.R.: Where's the charge? Protonation sites in gaseous ions change with hydration. J. Am. Chem. Soc. 134, 15805-15813 (2012)

28. Chai, Y., Hu, N., Pan, Y.: Kinetic and thermodynamic control of protonation in atmospheric pressure chemical ionization. J. Am. Soc. Mass Spectrom. 24, 1097-1101 (2013)

29. Joyce, J.R., Richards, D.S.: Kinetic control of protonation in electrospray ionization. J. Am. Soc. Mass Spectrom. 22, 360-368 (2011)

30. Szafran, M., Katrusiak, A., Dega-Szafran, Z., Komasa, A., Kowalczyk, I.: Structure of methyl 4-(trimethylammonium)benzoate iodide studied by Xray diffraction, DFT calculations, NMR and FTIR spectra. J. Mol. Struct. 1006, 330-336 (2011)

31. Frisch, M.J., Trucks, G.W., Schlegel, H.B., Scuseria, G.E., Robb, M.A., Cheeseman, J.R., Montgomery Jr., J.A., Vreven, T., Kudin, K.N., Burant, J.C., Millam, J.M., Iyengar, S.S., Tomasi, J., Barone, V., Mennucci, B., Cossi, M., Scalmani, G., Rega, N., Petersson, G.A., Nakatsuji, H., Hada, M., Ehara, M., Toyota, K., Fukuda, R., Hasegawa, J., Ishida, M., Nakajima, T., Honda, Y., Kitao, O., Nakai, H., Klene, M., Li, X., Knox, J.E., Hratchian, H.P., Cross, J.B., Adamo, C., Jaramillo, J., Gomperts, R., Stratmann, R.E., Yazyev, O., Austin, A.J., Cammi, R., Pomelli, C., Ochterski, J.W., Ayala, P.Y., Morokuma, K., Voth, G.A., Salvador, P., Dannenberg, J.J., Zakrzewski, V.G., Dapprich, S., Daniels, A.D., Strain, M.C., Farkas, O., Malick, D.K., Rabuck, A.D., Raghavachari, K., Foresman, J.B., Ortiz, J.V., Cui, Q., Baboul, A.G., Clifford, S., Cioslowski, J., Stefanov, B.B., Liu, G., Liashenko, A., Piskorz, P., Komaromi, I., Martin, R.L., Fox, D.J., Keith, T., Al-Laham, M.A., Peng, C.Y., Nanayakkara, A., Challacombe, M., Gill, P.M.W., Johnson, B., Chen, W., Wong, M.W., Gonzalez, C., Pople, J.A.: Gaussian 03, Revision B. Gaussian, Inc., Pittsburgh (2003)

32. Bortolini, O., Fantin, G., Ferretti, V., Fogagnolo, M., Giovannini, P.P., Medici, A.: Relative acidity scale of bile acids through ESI-MS measurements. Org. Biomol. Chem. 8, 3674-3677 (2010)

33. Hunter, E.P.L., Lias, S.G.: Evaluated gas phase basicities and proton affinities of molecules: an update. J. Phys. Chem. Ref. Data 27, 413-656 (1998)

34. Laufer, D.A., Gelb, R.I., Schwartz, L.M.: ${ }^{13}$ C NMR determination of acidbase tautomerization equilibria. J. Org. Chem. 49, 691-696 (1984)

35. Tu, Y.-P.: Dissociative protonation sites: reactive centers in protonated molecules leading to fragmentation in mass spectrometry. J. Org. Chem. 71, 5482-5488 (2006)

36. Chai, Y., Guo, C., Jiang, K., Pan, Y., Sun, C.: C-C and C-N bond cleavage in the dissociation of protonated $N$-benzyllactams: dissociative proton transfer and intramolecular proton-transport catalysis. Org. Biomol. Chem. 10, 791-797 (2012)

37. Levsen, K., Schiebel, H.-M., Terlouw, J.K., Jobst, K.J., Elend, M., Preiß, A., Thiele, H., Ingendoh, A.: Even-electron ions: a systematic study of the neutral species lost in the dissociation of quasi-molecular ions. J. Mass Spectrom. 42, 1024-1044 (2007)

38. Zhang, X., Wang, H., Liao, Y., Ji, H., Guo, Y.: Study of methylation of nitrogen-containing compounds in the gas phase. J. Mass Spectrom. 42, 218-224 (2007)

39. Kuck, D.: Mass spectrometry of alkylbenzenes and related compounds. Part 11. Gas phase ion chemistry of protonated alkylbenzenes (alkylbenzenium ions). Mass Spectrom. Rev. 9, 583-630 (1990) 
40. Cech, N.B., Enke, C.G.: Practical implications of some recent studies in electrospray ionization fundamentals. Mass Spectrom. Rev. 20, 362-387 (2001)

41. Sunner, J., Nicol, G., Kebarle, P.: Factors determining relative sensitivity of analytes in positive mode atmospheric pressure ionization mass spectrometry. Anal. Chem. 60, 1300-1307 (1988)
42. Andrade, F.J., Shelley, J.T., Wetzel, W.C., Webb, M.R., Gamez, G., Ray, S.J., Hieftje, G.M.: Atmospheric pressure chemical ionization source. 1. Ionization of compounds in the gas phase. Anal. Chem 80, 2646-2653 (2008)

43. Terrier, P., Desmazières, B., Tortajada, J., Buchmann, W.: APCI/APPI for synthetic polymer analysis. Mass Spectrom. Rev. 30, 854-874 (2011) 